\title{
Is it worth allowing the presence of morning stiffness in the definition of inactive disease in juvenile idiopathic arthritis?
}

\author{
Maddalena Allegra', Maria Chiara Gallo', Sara Verazza', Serena Calandra', Sara Dalprà', Federica Mongelli',
} Alberto Martini ${ }^{1,2}$, Angelo Ravelli ${ }^{2,3}$, Alessandro Consolaro ${ }^{1 *}$

From 21st European Pediatric Rheumatology (PReS) Congress

Belgrade, Serbia. 17-21 September 2014

\section{Introduction}

Morning stiffness is a major symptom of juvenile idiopathic arthritis (JIA) and it is usually associated with active disease. However, it is common view that children with disease quiescence may have some degrees of residual morning stiffness. The 2004 preliminary criteria for inactive disease (ID) in JIA did not include the assessment of morning stiffness, whereas the 2011 revision of the criteria has allowed the presence of morning stiffness lasting $\leq 15$ minutes. However, it is still unknown whether the disease status of children with ID who have or do not have morning stiffness is comparable.

\section{Objectives}

To compare the disease status of children with JIA who meet the 2011 revised criteria for ID and have or do not have a morning stiffness lasting $\leq 15$ minutes.

\section{Methods}

A database at the study center including 785 patients who had undergone a total of 2957 visits, which included a parent report of the presence and duration of morning stiffness, was analyzed to identify all visits in which patients met the criteria for ID. In each visit, the duration of morning stiffness was categorized as follows:

Table 1

\begin{tabular}{|c|c|c|c|c|}
\hline \multicolumn{5}{|c|}{ Patients meeting 2004 ID criteria } \\
\hline \multicolumn{5}{|c|}{ Patients meeting 2011 ID criteria } \\
\hline & $\begin{array}{l}\text { No MS } \\
N=390\end{array}$ & $\begin{array}{c}M S \leq 15 \mathrm{~min} \\
\mathrm{~N}=41\end{array}$ & $\begin{array}{c}M S>15 \text { min } \\
N=29\end{array}$ & p-value \\
\hline Median (IQR) disease duration & $3.8(1.8 ; 7.3)$ & $2.8(1.4 ; 6)$ & $5.7(2.6 ; 7.9)$ & 0.30 \\
\hline Functional ability (JAFS score) $>0, N(\%)$ & $64(16.4)$ & $18(43.9)$ & $23(79.3)$ & $<0.001$ \\
\hline Physical health (PRQL PhS) >0, N (\%) & $173(44.4)$ & $32(78)$ & $28(96.6)$ & $<0.001$ \\
\hline Psychosocial health (PRQL PhS) >0, N (\%) & $188(48.2)$ & $29(70.7)$ & $24(82.8)$ & $<0.001$ \\
\hline VAS well-being >0, N (\%) & $155(40.4)$ & $32(82.1)$ & $28(100)$ & $<0.001$ \\
\hline VAS pain $>0, N(\%)$ & $102(26.8)$ & $28(68.3)$ & $21(87.5)$ & $<0.001$ \\
\hline Acceptable symptom state, N (\%) & $366(95.6)$ & $33(80.5)$ & $16(57.1)$ & $<0.001$ \\
\hline
\end{tabular}

MS: morning stiffness; IQR: interquartile range

'Pediatria II, Istituto Giannina Gaslini, Genova, Italy

Full list of author information is available at the end of the article 
$\leq 15 \mathrm{~min}, 15-30 \mathrm{~min}, 30-60 \mathrm{~min}, 1-2 \mathrm{hr},>2 \mathrm{hr}$. Clinical assessments included demographic features, and parentreported outcomes. In case a patient met the ID criteria in more than 1 visit, only the first visit was retained.

\section{Results}

A total of 460 visits in which the patient met the criteria for ID were evaluated. Absence of morning stiffness was reported in $390(84.8 \%)$ visits, whereas in 70 visits (15.2\%) there was morning stiffness. Among the visits with morning stiffness, in 41 (8.9\%) duration was $\leq 15 \mathrm{~min}$, and in $29(6.3 \%)$ duration was $>15 \mathrm{~min}$. Table 1 shows the comparison of disease duration and parent-reported outcomes between patients with absence or presence of morning stiffness.

\section{Conclusion}

Among patients who met the 2011 criteria for ID, those with morning stiffness $\leq 15 \mathrm{~min}$ had worse parentreported outcomes than those without morning stiffness. This finding suggests that parents may not perceive their child's disease state as true remission when lower degrees of morning stiffness are present. Notably, a sizeable proportion $(6.3 \%)$ of children meeting the 2004 ID criteria had morning stiffness lasting $>15 \mathrm{~min}$. The change of the criterion "Duration of morning stiffness of $\leq 15$ minutes" to "Absence of morning stiffness" in the definition for ID should be considered.

\section{Disclosure of interest}

None declared

\section{Authors' details}

'Pediatria II, Istituto Giannina Gaslini, Genova, Italy. ${ }^{2}$ Pediatrics, Università degli Studi di Genova, Italy. ${ }^{3}$ Pediatrics, Istituto Giannina Gaslini, Genova, Italy.

Published: 17 September 2014
Submit your next manuscript to BioMed Central and take full advantage of:

- Convenient online submission

- Thorough peer review

- No space constraints or color figure charges

- Immediate publication on acceptance

- Inclusion in PubMed, CAS, Scopus and Google Scholar

- Research which is freely available for redistribution

Submit your manuscript at www.biomedcentral.com/submit 